\title{
Use of Frailty to Predict Survival in Elderly Patients With Early Stage Non-Small-Cell Lung Cancer Treated With Stereotactic Body Radiation Therapy
}

\section{Citation}

Franco, Idalid. 2017. Use of Frailty to Predict Survival in Elderly Patients With Early Stage Non-Small-Cell Lung Cancer Treated With Stereotactic Body Radiation Therapy. Doctoral dissertation, Harvard Medical School.

\section{Permanent link}

http://nrs.harvard.edu/urn-3:HUL.InstRepos:40621031

\section{Terms of Use}

This article was downloaded from Harvard University's DASH repository, and is made available under the terms and conditions applicable to Other Posted Material, as set forth at http:// nrs.harvard.edu/urn-3:HUL.InstRepos:dash.current.terms-of-use\#LAA

\section{Share Your Story}

The Harvard community has made this article openly available. Please share how this access benefits you. Submit a story. 


\section{Title Page}

\section{Scholarly Report submitted in partial fulfillment of the MD Degree at Harvard Medical School}

Date: 01 February 2017

Student Name: Idalid Franco, BA

Scholarly Report Title: Use of Frailty to Predict Survival in Elderly Patients with Early Stage Non-Small-Cell Lung Cancer Treated with Stereotactic Body Radiation Therapy

Mentor Name and Affiliations: Raymond H. Mak, MD, Department of Radiation Oncology, DanaFarber Cancer Institute, Brigham and Women's Hospital, Harvard Medical School

Collaborators, with Affiliations: Yu-Hui Chen, Department of Biostatistics and Computational Biology, Dana-Farber Cancer Institute

Fallon Chipidza, MD, Department of Radiation Oncology, Dana-Farber Cancer Institute, Brigham and Women's Hospital, Harvard Medical School

Vishesh Agrawal, Department of Radiation Oncology, Dana-Farber Cancer Institute, Brigham and Women's Hospital, Harvard Medical School

John Romano, BA, Department of Radiation Oncology, Dana-Farber Cancer Institute, Brigham and Women's Hospital

Elizabeth Baldini, MD,MPH, Department of Radiation Oncology, Dana-Farber Cancer Institute, Brigham and Women's Hospital, Harvard Medical School

Aileen Chen, MD, MPP, Department of Radiation Oncology, Dana-Farber Cancer Institute, Brigham and Women's Hospital, Harvard Medical School

Yolonda Colson, MD, PhD, Division of Thoracic Surgery, Brigham and Women's Hospital, Boston, MA; Harvard Medical School

Ying Hou, MD, Department of Radiation Oncology, Dana-Farber Cancer Institute, Brigham and Women's Hospital

David Kozono, MD, PhD, Department of Radiation Oncology, Dana-Farber Cancer Institute, Brigham and Women's Hospital, Harvard Medical School

Jon Wee, MD, Division of Thoracic Surgery, Brigham and Women's Hospital, Boston, MA; Harvard Medical School 


\section{$\underline{\text { Abstract }}$ \\ TITLE: Use of Frailty to Predict Survival in Elderly Patients with Early Stage Non-Small-Cell Lung Cancer Treated With Stereotactic Body Radiation Therapy}

Idalid Franco, Yu-Hui Chen, Fallon Chipidza, Vishesh Agrawal, John Romano, Elizabeth Baldini, Aileen Chen, Yolonda Colson, Ying Hou, David Kozono, Jon Wee, Raymond Mak

Purpose: Frailty has been shown to increase morbidity and mortality independent of age, but studies are lacking in radiation oncology. This study evaluates a modified frailty index (mFI) in predicting overall survival (OS) and non-cancer death for Stage I/II [NOM0] Non-Small-Cell Lung Cancer (NSCLC) patients treated with Stereotactic Body Radiation Therapy (SBRT).

Methods: Medical records for all patients with Stage I/II NSCLC treated at our institution with SBRT from 2009-2014 were reviewed. A validated mFI score, consisting of 11 variables was calculated, classifying patients as non-frail $(0-1)$ or frail $(\geq 2)$. Primary endpoint (OS) was analyzed using KaplanMeier method and log-rank. Secondary endpoint, non-cancer death, was analyzed using Fine-Gray's method, with death from lung cancer as a competing risk.

Results: Patient cohort consisted of 38 (27.3\%) non-frail and 101 (72.7\%) frail [median total mFI score 3.0 (range 0-7)]. Median age and pack-year history was 74 and 46 years, respectively. Median follow-up among survivors was 38.5 months (range 4.0-74.1 months). Frailty was associated with a lower 3-year OS $(37.3 \%$ vs. $74.7 \% ; p=0.004)$ and 3 -year cumulative incidence of non-cancer death $(36.7 \%$ vs. $12.5 \%$; $\mathrm{p}=0.02$ ). Frailty remained significant in the multivariate model $[\mathrm{OS} H R$ for $\mathrm{mFI} \geq 2: 2.25(1.14-4.44)$; $\mathrm{p}=0.02]$.

Conclusion: Frailty is associated with lower OS in elderly patients with early stage NSCLC treated with SBRT, yet frail patients survived a median 2.5 years, and were more likely to die of causes unrelated to the primary lung cancer, suggesting SBRT should be considered even in older patients deemed unfit for surgery. 


\section{Table of Contents:}

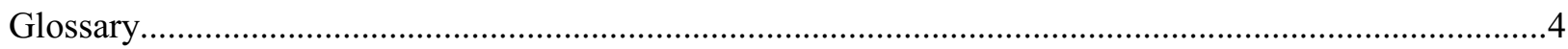

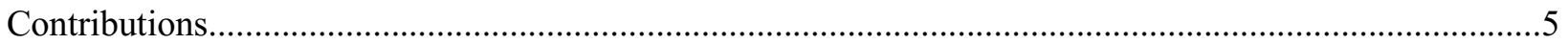

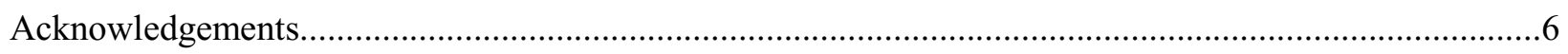

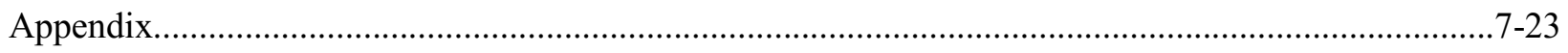




\section{Glossary:}

CI: Cummulative Index

CT: Computed Tomography

CTCAE: Common Terminology Criteria for Adverse Events

Gy: Gray

mFI: Modified Frailty Index

NSCLC: Non-Small-Cell Lung Cancer

OS: Overall Survival

RTOG: Radiation Therapy Oncology Group

SBRT: Stereotactic Body Radiation Therapy 


\section{Contributions to the work:}

As the first author on this manuscript, I had the principal role designing the project, including initial formulation of the goals and aims of the paper. With the assistance of the project mentor, Dr. Raymond Mak, we decided to study the role of frailty in outcomes for early stage lung cancer patients and I set out to conduct literature reviews on appropriate indices and what was known in the field. I found that frailty had not been explored within radiation oncology, but similar fields including medical oncology and surgical oncology had applicable data on the role of frailty in cancer patients and treatment outcomes. Based on the similarity of the patient population to the surgical early non-small-cell lung cancer population I decided that the modified frailty index (mFI), previously studied in surgical oncology, could serve as an appropriate metric for our outcome of interest. I used the existing database created to evaluate outcome of Stereotactic Body Radiation Therapy on lung cancer patients and added the eleven variables needed to determine the composite mFI. This database was maintained at the time by the research assistant, John Romano, who helped design the software for data collection. In addition to the frailty variables, outcomes and descriptive variables were also necessary and were collected and recorded in the medical record by the radiation oncologist and surgical oncologist that also served as collaborators on the project: Drs. Elizabeth Baldini, Aileen Chen, Yolonda Colson, David Kozono, Jon Wee and Raymond Mak. Data was extracted and entered into the RedCap Software by myself, Fallon Chipidza, Vishesh Agrawal, John Romano, and Ying Hou. Once all the data was recorded I went through and verified that all entries were correct and valid. I then performed data cleaning and initial statistical analysis in SAS, with Drs. Raymond Mak and Vishesh Agrawal helping me troubleshoot and think through how to best approach the research question including conducting a secondary analysis for competing risks. Once I had completed the initial analysis, I completed descriptive tables and figures and took the code to our statistician, Yu-Hui Chen, who verified the statistical output and helped me create the final figures and tables for the manuscript submission. Once all this was completed I composed the first draft of the paper which was sent out to all the co-authors for feedback and additional guidance. All authors provided valuable feedback in manuscript structure and data presentation. Drs. Elizabeth Baldini, Aileen Chen, Yolonda Colson, David Kozono, Jon Wee and Raymond Mak provided expert opinions on technical aspects of the paper and valuable references to include in the final submission. Once the paper had undergone multiple revisions all authors approved the final manuscript and suggested potential reviewers. The project mentor and I reviewed potential submission venues that were most appropriate for the manuscript topic and decided on the Journal of Geriatric Oncology. I then went through the submission process and am awaiting a final decision from the editors. 


\section{Acknowledgements:}

I would like to acknowledge my collaborators at the Dana Farber Cancer Institute and Brigham and Women's Hospital for their support throughout the entirety of the project. I am particularly grateful for the mentorship of Dr. Raymond Mak and his guidance in the inception and completion of this

project and Dr. Elizabeth Klerman, Holmes Society research fellow in the Scholars in Medicine Office, for her constant encouragement and wisdom to anticipate and prevent potential roadblocks. I also want to acknowledge the funding support from Dr. Raymond Mak and the Scholars in Medicine office at Harvard Medical School. 


\section{$\underline{\text { Appendix 1: }}$}

\section{Manuscript Submitted for Publication}

\section{Introduction}

While cigarette smoking has continued to decline in the United States over the past decade, lung cancer remains the malignancy with the second highest incidence and highest number of estimated deaths for both men and women. Non-Small-Cell Lung Cancer (NSCLC), the most common type of lung cancer, composes $85-90 \%$ of lung cancers, with surgical resection as the treatment of choice. Yet, for many older patients, the risk of postoperative morbidity and mortality is not trivial, and radiation treatment has become an attractive modality in treating this sicker patient population. ${ }^{[1],[2],[3] \text { and [4] }}$

Although more than one-third of cancers are diagnosed in adults over age 70, chronological age alone appears to be a poor predictor of treatment tolerance and outcomes. ${ }^{5}$ Functional status, cognition, and comorbidities are variable in older patients and can also influence tolerance to cancer therapy. Reports from the American Geriatric Society and National Institute on Aging have emerged in recent years highlighting the importance of understanding the clinical definition and physiological characteristics encompassing vulnerability intrinsic in frail adults. ${ }^{6}$

The multidomain definition of frailty, comprised of the cumulative effect of individual deficits in physical, cognitive, functional and social domains, has been used throughout the medical literature. ${ }^{7}$ Frailty, defined through a modified frailty index $(\mathrm{mFI})$, has gained popularity in the surgical field as a reliable means of predicting morbidity and mortality in vulnerable elderly populations. Multiple studies have shown the mFI to accurately stratify patients at increased risk of postoperative delirium, institutionalization, readmission, and increased length of stay. ${ }^{[8], ~[9], ~[10] ~ a n d ~[11] ~ T h i s ~} \mathrm{mFI}$, created by mapping 11 variables available in the American College of Surgeons National Surgical Quality Improvement Program (NSQIP) to the Canadian Study of Health and Aging Frailty Index (CSHA-FI), has been shown to be useful in preoperative patient selection to minimize negative outcomes for early stage NSCLC patients undergoing lobectomy. ${ }^{[12]}$ and [13]

Historically, conventional radiotherapy or watchful waiting were the only options available for nonsurgical candidates. ${ }^{[14]}$ and ${ }^{[15]}$ A meta-analysis of conventional radiotherapy for NSCLC by Qiao et al. looking at 18 papers published between 1988 and 2000 found a 3-year OS of 34\%. ${ }^{16}$ Outcomes drastically improved with the development of Stereotactic Body Radiation Therapy (SBRT), and prospective studies have demonstrated substantially higher primary tumor control, with a low risk of severe toxicity, compared to conventional radiotherapy ${ }^{[17]}$ and ${ }^{[18]}$, making SBRT the guideline-recommended treatment of 
choice for peripherally located, early stage NSCLC in medically inoperable patients, or those refusing surgery. ${ }^{4}$

Despite development of this effective treatment option for high-risk NSCLC patients, the current U.S. Preventive Services Task Force recommendation of annual CT screening for lung cancer excludes those patients unable or unwilling to have curative surgery. ${ }^{19}$ This is likely due to high-risk patients having multiple competing causes of death, including chronic obstructive lung disease, coronary artery disease, and other smoking related diseases that outweigh the potential long-term benefits of cancer treatment. ${ }^{18}$ The fact remains that overall risk-benefit ratios must be understood within the heterogeneous aging population to better guide treatments.

Despite the growing literature describing the usefulness of frailty in risk stratification for surgery and medicine, to our knowledge there are no prior studies assessing frailty within the field of Radiation Oncology. As the proportion of nonsurgical thoracic oncology patients continues to increase, it becomes crucial to incorporate baseline metrics of overall fitness, which are more predictive than age, to identify older cancer patients most at risk for adverse outcomes. The current study evaluates the use of the mFI in predicting overall survival and risk of non-cancer death for Stage I/II (NOM0) NSCLC patients treated with SBRT.

\section{Materials and Methods}

\subsection{Patients}

With Institutional Review Board approval, medical records for all patients with Stage I/II (N0M0) NSCLC treated with SBRT in our department from 2009-2014 were reviewed. NSCLC Stage I/II (N0M0) was defined per the American Joint Committee on Cancer (AJCC 7th edition) ${ }^{20}$, with the highest classification as Stage IIA [T2b N0 M0]: tumor more than $5 \mathrm{~cm}$ but $7 \mathrm{~cm}$ or less in greatest dimension [T2b], no regional lymph node metastasis [N0], no distant metastasis [M0]. Patient, tumor, treatment characteristics, and outcomes data were collected. Patients who received SBRT for locally recurrent disease, local progression of advance stage disease, small cell lung cancer, or metastases to the lung from other sites of primary disease were excluded. In nine patients who underwent two SBRT treatments for two primary lung cancers, only data from the most recent SBRT treatment was used.

\subsection{Endpoints}

Data on patient vital statistics were updated through December 2015. Information on death was obtained from electronic medical records as well as the U.S. Social Security Death Index database. ${ }^{21}$ Information on cause of death was obtained from the medical record, when available, and categorized as: death of disease, death of other causes, and death of unknown causes. There were no deaths due to treatmentrelated toxicity. The endpoints for overall survival (OS) in the survival analysis were calculated from the 
start date of radiation therapy (SBRT) to the date of death or last date known alive. For competing risk analyses, other and unknown causes of death were combined and compared to death from lung cancer.

Data on recurrence was categorized as per RTOG $0236^{17}$ : (1) primary tumor recurrence [tumor recurrence in-field or within $1 \mathrm{~cm}$ of planning target volume], (2) lobar recurrence [including primary tumor and recurrence in the same lobe], (3) local/regional recurrence [composite of lobar recurrence and hilar/mediastinal recurrences], and (4) distant metastases. Recurrence-Free Survival (RFS) was determined from date of first radiation treatment to date of any recurrence or death; whichever came first (with censoring of patients at last disease assessment who died without documented recurrence and death occurred greater than 6 months from date of last disease assessment). Toxicity was graded per CTCAE v4.0. Rib fracture was recorded as a binary variable.

\subsection{Treatment Approach}

All patients were evaluated by a thoracic surgeon and radiation oncologist and deemed to be inoperable or borderline operable, and opted for treatment with SBRT. Patients were treated with SBRT per institutional norms to a dose of 10 to 12 Gy x 5 fractions for tumors adjacent to chest wall or central tumors, and 18 Gy x 3 fractions for peripheral tumors. Follow-up occurred every 3 to 4 months after treatment for the first 2 years with a chest CT, then every 6 months for the next three years, and annually thereafter.

\subsection{Modified Frailty Index}

The validated $\mathrm{mFI}$ score, consisting of 11 variables was calculated by assigning one point for each of the following: performance status $\geq 2$, impaired sensorium, diabetes mellitus, chronic/acute lung disease, myocardial infarction in past $\leq 6$ months, hospitalization for congestive heart failure in past $\leq 6$ months, coronary or cardiac disease, hypertension on medications, history of transient ischemic attack, cerebrovascular accident or stroke with neurological deficits, and peripheral vascular disease. Frailty status was defined as non-frail (score $0-1$ ) and frail (score $\geq 2$ ), as previously described in the literature. ${ }^{[9]}$ and [10]

\subsection{Statistical Analyses}

Descriptive statistics were assessed for pre-treatment patient, tumor characteristics, and $\mathrm{mFI}$ components. The distribution of characteristics by frailty status was performed using Chi-square /Fisher's exact test or Wilcoxon Rank-Sum. Time-to-event outcomes were analyzed using the Kaplan-Meier method and logrank test. Multivariate Cox Proportional Hazards model for OS was created via stepwise selection with $\mathrm{p}=0.15$ as the inclusion and removal criteria. As a secondary analysis, the risk of non-cancer death was analyzed by frailty status using Fine-Gray's method with death from lung cancer as a competing risk. 
Study data were collected and managed using REDCap electronic data capture tools hosted at our institution. ${ }^{22}$ Statistics were performed using SAS version 9.4 (SAS Institute, Cary, NC) with competing risk analysis done in R version 2.10.0 (R Foundation, Vienna, Austria). Two-sided p-values were used, and p-values less than 0.05 were considered statistically significant.

\section{Results}

\subsection{Patient Characteristics}

The study cohort consisted of 139 patients with early stage NSCLC treated with SBRT. Pretreatment characteristics for all patients and comparison by frailty status are shown in Table 1. Median age was 74 years [Interquartile Range 66, 80], median pack-year smoking history was 46 [IQR 30, 65] and median Body Mass Index (BMI) was 25.7 [IQR 22.4, 30.5]. Fifty-two percent of the population consisted of women. Most common histology was adenocarcinoma at $43 \%$, followed by squamous cell carcinoma at $25 \%$. Over $85 \%$ of patients had Stage IA disease and $84.9 \%$ were T1. Comparisons by frailty status showed frail patients were older $(54.5 \%$ vs. $34.2 \%$ above age $74 ; p=0.04)$ and had a more extensive smoking history (50 vs. 40 pack-years; $\mathrm{p}=0.01$ ).

In looking at the entire patient cohort, with respect to the eleven components comprising the modified frailty index $(\mathrm{mFI})$, seven factors were significantly higher in the frail group compared to the non-frail group (Table 2). These included: hypertension on medications $(75.3 \%$ vs. $34.2 \%$; $<<0.0001)$, history of hospitalization due to chronic obstructive pulmonary disease or pneumonia $\leq 6$ months $(60.4 \% \mathrm{vs.} 15.8 \%$; $\mathrm{p}<0.0001)$, history of $\mathrm{CAD}(53.3 \%$ vs. $5.3 \%$; p $<0.0001)$, performance status $\geq 2$ (49.5\% vs. 5.3\%; $\mathrm{p}<0.0001)$, history of diabetes mellitus $(36.6 \%$ vs. $2.6 \%$; $<0.0001)$, history of transient ischemic attack $(16.8 \%$ vs. $0.0 \% ; p=0.004)$ and history of peripheral vascular disease $(26.7 \%$ vs. $2.6 \% ; p=0.0008)$. The remaining four factors were not statistically different between groups.

\subsection{Outcomes}

The median follow-up time among survivors was 38.5 months (range 4.0-74.1 months). Outcomes are shown in Table 3. Frail patients had a statistically significant lower 3-year OS than non-frail patients (37.3\% vs. 74.7\%; $\mathrm{p}=0.003$; Figure 1) and higher Cumulative incidence (CI) of non-cancer death (3-year CI $44.1 \%$ vs. $12.5 \%$; $\mathrm{p}=0.02$; Figure 2). Three-year Recurrence-Free Survival was lower in the frail group (34.2\% vs. $62.2 \%$; $=0.005)$, with three-year recurrence free rates, either within the area of the primary tumor or lobe, significantly lower for the frail group. There was a low incidence of treatment-related toxicities, all grade 3 or lower, with no significant differences between groups. 


\subsection{Univariate and Multivariate Analysis}

On univariate analysis, significant adverse predictors for OS included frail status, male gender, and increased pack-years of smoking (Table 4). On multivariate analysis, both frailty [HR 2.25; (1.14-4.44); $\mathrm{p}=0.02]$ and smoking remained associated with OS.

A secondary analysis for competing risks (Table 5) showed frailty as significantly associated with increased non-cancer mortality (lung cancer death as a competing risk) [HR for $\mathrm{mFI} \geq 2$; 2.66 (1.15-6.14); $\mathrm{p}=0.02]$. On a competing risk, univariate analyses for lung cancer-specific survival (with death from other causes as a competing event), only pack-years of smoking was significant [HR 1.01; (1.00-1.02); $\mathrm{p}=0.02]$.

\section{Discussion}

In this study of early stage NSCLC patients treated with SBRT, we found that frailty, defined by an mFI $\geq 2$, was significantly associated with a lower OS and higher risk of non-cancer death. However, the fact that frail patients in this study had a 3 -year OS of $\sim 40 \%$, median survival $>2.5$ years, and three year local failure of $21 \%$, compared to the 3-year OS of $34 \%$ and three year local failure of $40 \%$ found by Qiao et al., prior to SBRT, suggests that this treatment modality may still be beneficial for patients who are too frail for surgery, chemotherapy, or other modalities. ${ }^{23}$ Additionally, the significant difference in outcomes seen between frail and non-frail patients found in our study highlights the important role that frailty can play in stratifying overall risk-benefit ratios within the heterogeneous aging population.

To our knowledge, the use of the mFI to predict outcomes has never been reported in radiation oncology, and the impact of frailty in patients treated with RT is poorly understood. The advantages of applying the $\mathrm{mFI}$ to understand prognosis and life expectancy in patients under evaluation for RT include: 1) simple interpretation with a binary question of whether a patient has more than one component of the mFI; 2) ease of obtaining this information from the patient and/or medical record. The use of the $\mathrm{mFI}$ in Radiation Oncology can meaningfully enhance the discussion between the patient and provider when discussing expectations and predicted outcomes. Importantly, the mFI considers performance status, assigning one point for performance status $\geq 2$, a variable which is not considered by the Charlson Comorbidity Index (CCI), but has been found to be a significant, independent prognostic factor in NSCLC. ${ }^{24}$ The mFI also considers recent respiratory and cardiac events, $\leq 6$ months, whereas the CCI does not account for the timeline of recent events, which can decrease a patient's physiological reserve to adequately recover from additional stressors, and have been found to be important in determining outcomes for NSCLC patients treated with SBRT. ${ }^{25}$ While it was not the focus of our paper to do a comparison between the use of the $\mathrm{CCI}$ and $\mathrm{mFI}$ in predicting outcomes, a secondary analysis incorporating both indices in the final model showed frailty continued to be a significant predictor of overall survival whereas CCI lost significance after accounting for all other covariables. Further studies will be necessary to fully elucidate the role that 
both frailty and comorbidities play in predicting outcomes for this aging population, but this finding underscores the importance of considering novel metrics, such as frailty, to inform shared decision making in the aging population.

Our study also highlights the potential usefulness of the mFI as a risk stratification tool that can be utilized by surgeons and radiation oncologists in multidisciplinary teams to identify optimal local therapy for high-risk patients. The $\mathrm{mFI}$ has been used in surgical series as a tool for predicting morbidity and mortality in thoracic surgery and the findings of the current study show it may also be a valuable predictive tool in radiation oncology. ${ }^{[26]}$ and ${ }^{[27]}$ Results of the current study also illustrate the survival benefits of SBRT for high risk patients, and the potential impact this may have on screening guidelines which currently exclude patients unable or unwilling to have curative surgery. ${ }^{19}$ One other important finding that highlights the need to stratify results of SBRT outcomes by frailty status is seen when comparing the current findings to those seen in the Indiana Study (RTOG 0236), a prospective Phase II trial for SBRT in medically inoperable patients with a current 50 month follow time. ${ }^{17}$ In the Indiana study the OS at 3-years was reported to be $42.7 \%$, similar to that seen at our institution $46.2 \%$. Yet, when this overall survival is further stratified into non-frail and frail patients we see that there is a striking difference between groups with 3 -year OS of non-frail at $74.7 \%$ compared to $37.3 \%$ in the frail population $(\mathrm{p}=0.003)$. Therefore, a better understanding of frailty status, even within this high-risk lung cancer population, has the potential to improve patient risk stratification, and is critical to better identify cancer patients that are likely to benefit from, and tolerate, more aggressive treatments, helping reduce the underutilization of cancer screening and treatments in older patients. ${ }^{[28] \text { and [29] }}$

Given the prevalence of smoking in medically inoperable NSCLC patients, it is also important to understand the interaction between $\mathrm{mFI}$ and smoking status. In the Canadian Study of Health and Aging, heavy smokers ( $>20$ pack-years) had a significantly higher frailty index, even when eliminating deficits consistently associated with smoking such as hypertension and cough. They also had higher mortality, due to any cause, than never smokers. Their study provided evidence that the associated inferior health status related to smoking could be captured through the frailty index. ${ }^{30}$ Our current study also found a strong association between $\mathrm{mFI}$ and pack-year history $(\mathrm{p}=0.013$ ), which is not surprising given the known correlation of smoking with components of the mFI such as cardiovascular conditions, COPD, and diabetes. Yet, frailty continued to be significant in predicting OS even after adjusting for pack-years $(p=0.02)$ and showed a trend toward significance for non-cancer specific mortality $(p=0.07)$.

These results should be interpreted in the context of the study design. Limitations to this study include weaknesses intrinsic to retrospective data collection and a relatively small sample size, such as incomplete data and follow-up. Additionally, the low incidence of severe toxicity and lack of patient- 
reported outcomes does not allow us to adequately model the association between frailty and SBRTtoxicity. Another limitation is the fact that we were not powered to look for patients who were extremely frail. The highest frailty score in our dataset was 6 , even though the frailty score is designed to go up to a value of 11. This is an important direction for future studies as it is possible that there is a point where a patient is too frail, even for a non-invasive procedure such as SBRT. Additionally, a sub analysis of the components of the modified frailty index most predictive of the outcomes of interest for SBRT could allow for the development of an even more targeted prediction model. Future analyses validating a more targeted index model with larger data sets and prospective data acquisition will be necessary to better characterize the impact of frailty on this patient population.

As frailty continues to become an emerging public health priority, our current study, and similar studies will play a pivotal role in describing the impact of frailty on outcomes after oncologic therapies. ${ }^{31}$ Our findings suggest that assessment of frailty, through a simple clinical tool, has the potential to help predict overall survival, identify patients most at risk for death of non-cancer causes, improve patient care in lung cancer and add valuable information for an informed dialogue between patients and providers. 


\section{References}

[1] Siegel RL, Miller KD, Jemal A. Cancer statistics, 2015. CA: a cancer journal for clinicians. 2015 Jan $1 ; 65(1): 5-29$.

[2] Mehta HJ, Ross C, Silvestri GA, Decker RH. Evaluation and treatment of high-risk patients with early-stage lung cancer. Clinics in chest medicine. 2011 Dec 31;32(4):783-97.

[3] Mokhles S, Nuyttens JJ, Maat AP, Birim Ö, Aerts JG, Bogers AJ, et al. Survival and treatment of nonsmall cell lung cancer stage I-II treated surgically or with stereotactic body radiotherapy: patient and tumor-specific factors affect the prognosis. Annals of surgical oncology. 2015 Jan 1;22(1):316-23.

[4] Howington JA, Blum MG, Chang AC, Balekian AA, Murthy SC. Treatment of stage I and II nonsmall cell lung cancer: diagnosis and management of lung cancer: American College of Chest Physicians evidence-based clinical practice guidelines. CHEST Journal. 2013 May 1;143(5_suppl):e278S-313S.

[5] Balducci L, Colloca G, Cesari M, Gambassi G. Assessment and treatment of elderly patients with cancer. Surgical oncology. 2010 Sep 30;19(3):117-23.

[6] Walston J, Hadley EC, Ferrucci L, Guralnik JM, Newman AB, Studenski SA, et al. Research agenda for frailty in older adults: toward a better understanding of physiology and etiology: summary from the American Geriatrics Society/National Institute on Aging Research Conference on Frailty in Older Adults. Journal of the American Geriatrics Society. 2006 Jun 1;54(6):991-1001.

[7] Handforth C, Clegg A, Young C, Simpkins S, Seymour MT, Selby PJ, et al. The prevalence and outcomes of frailty in older cancer patients: a systematic review. Annals of oncology. 2015 Jun 1;26(6):1091-101.

[8] Farhat JS, Velanovich V, Falvo AJ, Horst HM, Swartz A, Patton Jr JH, et al. Are the frail destined to fail? Frailty index as predictor of surgical morbidity and mortality in the elderly. Journal of Trauma and Acute Care Surgery. 2012 Jun 1;72(6):1526-31.

[9] Ehlert BA, Najafian A, Orion KC, Malas MB, Black JH, Abularrage CJ. Validation of a modified Frailty Index to predict mortality in vascular surgery patients. Journal of vascular surgery. 2016 Jun 30;63(6):1595-601.

[10] Chappidi MR, Kates M, Patel HD, Tosoian JJ, Kaye DR, Sopko NA, et al. Frailty as a marker of adverse outcomes in patients with bladder cancer undergoing radical cystectomy. InUrologic Oncology: Seminars and Original Investigations 2016 Jun 30 (Vol. 34, No. 6, pp. 256-e1). Elsevier. 
[11] Keller DS, Bankwitz B, Nobel T, Delaney CP. Using frailty to predict who will fail early discharge after laparoscopic colorectal surgery with an established recovery pathway. Diseases of the Colon \& Rectum. 2014 Mar 1;57(3):337-42.

[12] Mitnitski AB, Mogilner AJ, Rockwood K. Accumulation of deficits as a proxy measure of aging. The Scientific World Journal. 2001;1:323-36.

[13] Tsiouris A, Hammoud ZT, Velanovich V, Hodari A, Borgi J, Rubinfeld I. A modified frailty index to assess morbidity and mortality after lobectomy. Journal of Surgical Research. 2013 Jul 31;183(1):40-6.

[14] Raz DJ, Zell JA, Ou SI, Gandara DR, Anton-Culver H, Jablons DM. Natural history of stage I nonsmall cell lung cancer: implications for early detection. Chest Journal. 2007 Jul 1;132(1):193-9.

[15] McGarry RC, Song G, des Rosiers P, Timmerman R. Observation-only management of early stage, medically inoperable lung cancer: poor outcome. Chest Journal. 2002 Apr 1;121(4):1155-8.

[16] Qiao X, Tullgren O, Lax I, Sirzén F, Lewensohn R. The role of radiotherapy in treatment of stage I non-small cell lung cancer. Lung cancer. 2003 Jul 31;41(1):1-1.

[17] Timmerman RD, Hu C, Michalski J, Straube W, Galvin J, et al. Long-term results of RTOG 0236: A phase II trial of stereotactic body radiation therapy (SBRT) in the treatment of patients with medically inoperable stage I non-small cell lung cancer. International Journal of Radiation Oncology• Biology• Physics. 2014 Sep 1;90(1):S30.

[18] Nanda RH, Liu Y, Gillespie TW, Mikell JL, Ramalingam SS, Fernandez FG, et al. Stereotactic body radiation therapy versus no treatment for early stage non-small cell lung cancer in medically inoperable elderly patients: A National Cancer Data Base analysis. Cancer. 2015 Dec 1;121(23):4222-30.

[19] U.S. Preventive Services Task Force. Final Update Summary: Lung Cancer: Screening. Available from URL: http://www.uspreventiveservicestaskforce.org/Page/Document/UpdateSummaryFinal/lungcancer-screening [accessed July 15, 2016].

[20] Sobin LH, Gospodarowicz MK, Wittekind C, editors. TNM classification of malignant tumours. John Wiley \& Sons; 2011 Aug 31.

[21] "United States Social Security Death Index." database. FamilySearch. Http://FamilySearch.org : [accessed December 2015]. Citing U.S. Social Security Administration, Death Master File, database (Alexandria, Virginia: National Technical Information Service, ongoing).

[22] Harris PA, Taylor R, Thielke R, Payne J, Gonzalez N, Conde JG. Research electronic data capture (REDCap) - a metadata-driven methodology and workflow process for providing translational research informatics support. Journal of biomedical informatics. 2009 Apr 30;42(2):377-81. 
[23] Klement RJ, Belderbos J, Grills I, Werner-Wasik M, Hope A, Giuliani M, et al. Prediction of Early Death in Patients with Early-Stage NSCLC - Can We Select Patients without a Potential Benefit of SBRT as a Curative Treatment Approach?. Journal of Thoracic Oncology. 2016 Apr 7.

[24] Kawaguchi T, Takada M, Kubo A, Matsumura A, Fukai S, Tamura A, et al. Performance status and smoking status are independent favorable prognostic factors for survival in non-small cell lung cancer: a comprehensive analysis of 26,957 patients with NSCLC. Journal of Thoracic Oncology. 2010 May 31;5(5):620-30.

[25] Stephans KL, Djemil T, Reddy CA, Gajdos SM, Kolar M, Machuzak M, et al. Comprehensive analysis of pulmonary function Test (PFT) changes after stereotactic body radiotherapy (SBRT) for stage I lung cancer in medically inoperable patients. Journal of Thoracic Oncology. 2009 Jul 31;4(7):838-44.

[26] Velanovich V, Antoine H, Swartz A, Peters D, Rubinfeld I. Accumulating deficits model of frailty and postoperative mortality and morbidity: its application to a national database. journal of surgical research. $2013 \mathrm{Jul}$ 31;183(1):104-10.

[27] Dunne MJ, Abah U, Scarci M. Frailty assessment in thoracic surgery. Interactive cardiovascular and thoracic surgery. 2014 May 1;18(5):667-70.

[28] Chen RC, Royce TJ, Extermann M, Reeve BB. Impact of age and comorbidity on treatment and outcomes in elderly cancer patients. InSeminars in radiation oncology 2012 Oct 31 (Vol. 22, No. 4, pp. 265-271). WB Saunders.

[29] Corre R, Greillier L, Le Caër H, Audigier-Valette C, Baize N, Bérard H, Falchero L, et al. Use of a comprehensive geriatric assessment for the management of elderly patients with advanced non-small-cell lung cancer: The phase III randomized ESOGIA-GFPC-GECP 08-02 study. Journal of Clinical Oncology. 2016 May 1;34(13):1476-83.

[30] Hubbard RE, Searle SD, Mitnitski A, Rockwood K. Effect of smoking on the accumulation of deficits, frailty and survival in older adults: a secondary analysis from the Canadian Study of Health and Aging. JNHA-The Journal of Nutrition, Health and Aging. 2009 May 1;13(5):468-72.

[31] Cesari M, Prince M, Thiyagarajan JA, De Carvalho IA, Bernabei R, Chan P, et al. Frailty: An emerging public health priority. Journal of the American Medical Directors Association. 2016 Mar $1 ; 17(3): 188-92$. 
Figure 1: Kaplan-Meier curves of overall survival for frail and non-frail patients with Stage I/II NSCLC treated with SBRT

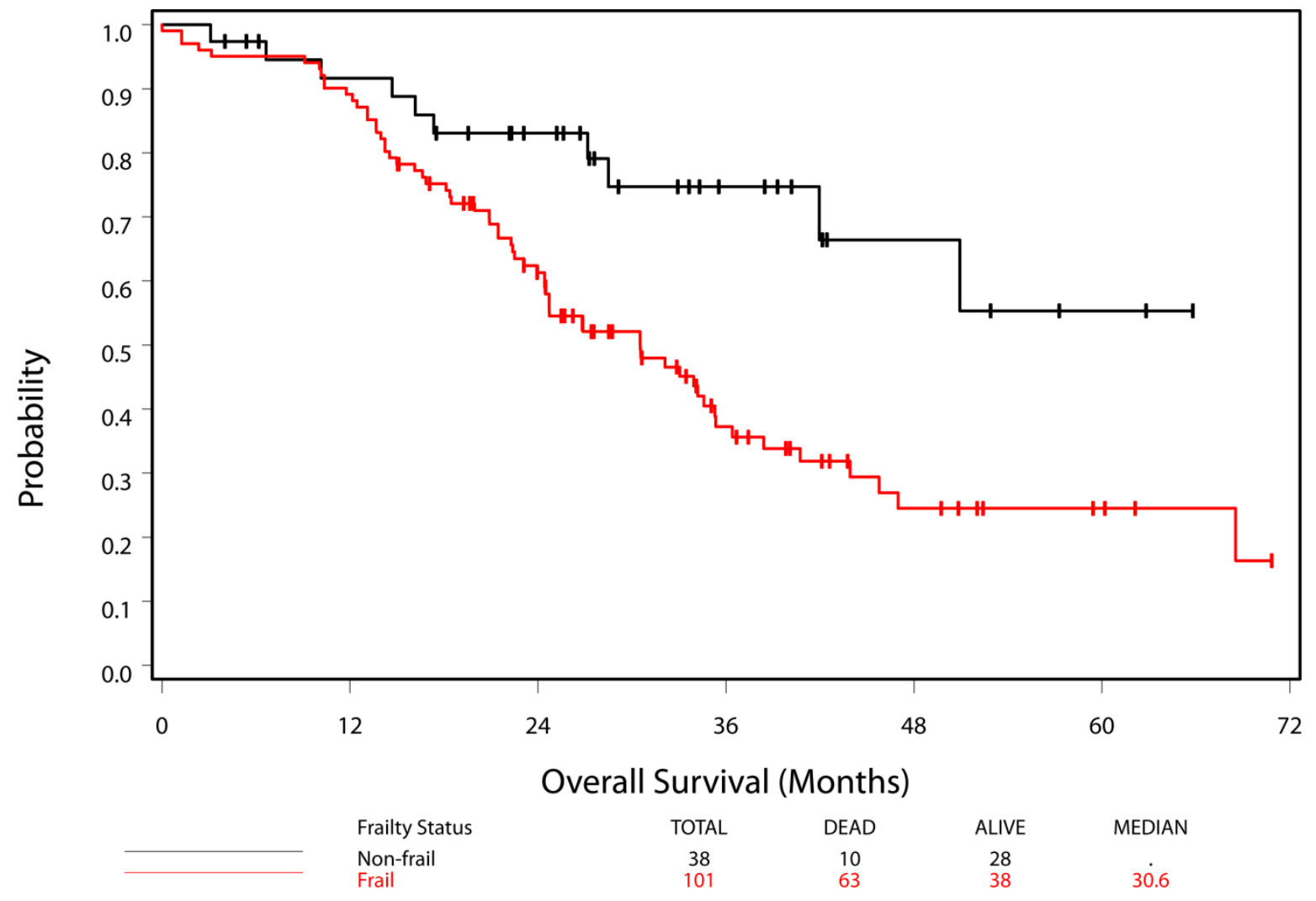


Figure 2: Cumulative incidence of non-cancer deaths by frailty status for patients with Stage I/II NSCLC treated with SBRT

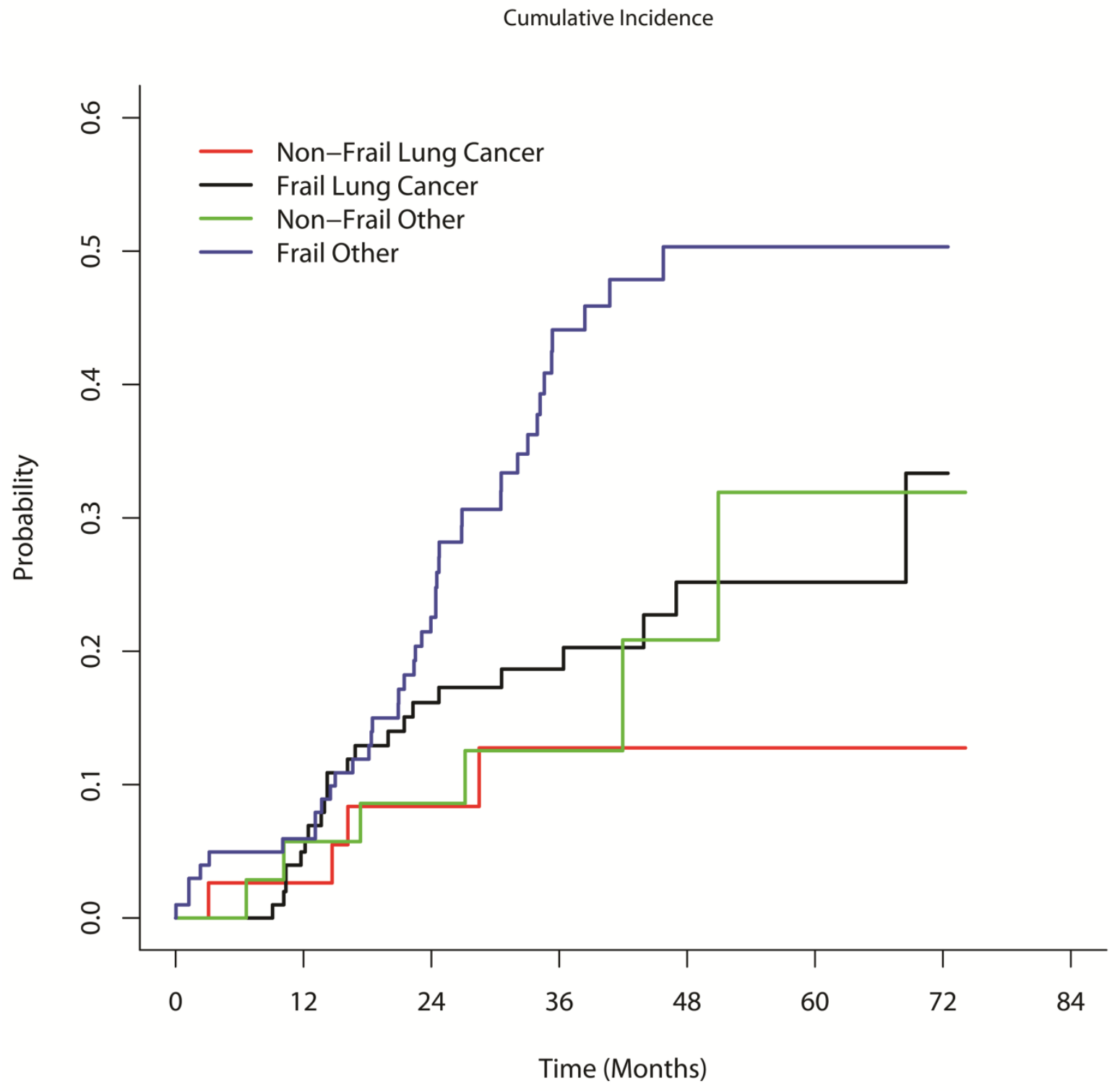


Table 1. Patient and Tumor Characteristics for patients with early stage NSCLC treated with SBRT with Comparisons by Frailty Status

\begin{tabular}{|c|c|c|c|c|}
\hline & All Patients & $\begin{array}{l}\text { Non-Frail } \\
\text { Patients } \\
(\mathrm{mFI}<2)\end{array}$ & $\begin{array}{l}\text { Frail Patients } \\
\qquad(\mathrm{mFI} \geq 2)\end{array}$ & p-value \\
\hline $\mathrm{N}$ & 139 & 38 & 101 & \\
\hline \multicolumn{5}{|l|}{ Age (years) } \\
\hline$\leq 74$ & $71(51.1 \%)$ & $25(65.8 \%)$ & $46(45.5 \%)$ & \\
\hline$>74$ & $68(48.9 \%)$ & $13(34.2 \%)$ & $55(54.5 \%)$ & 0.04 \\
\hline \multicolumn{5}{|l|}{ Gender } \\
\hline Female & $72(51.8 \%)$ & $25(65.8 \%)$ & $47(46.5 \%)$ & \\
\hline Male & $67(48.2 \%)$ & $13(34.2 \%)$ & $54(53.5 \%)$ & 0.06 \\
\hline Pack-years $^{\mathrm{a}}$ & 46 & 40 & 50 & \\
\hline Median [interquartile range] & {$[30,65]$} & {$[20,54]$} & {$[35,70]$} & 0.013 \\
\hline BMI $\left(\mathrm{kg} / \mathrm{m}^{2}\right)$ & 25.7 & 24.5 & 26.3 & \\
\hline Median [interquartile range] & {$[22.4,30.5]$} & {$[21.5,28.3]$} & {$[22.8,31.3]$} & 0.07 \\
\hline Previous cancer diagnosis & $85(61.2 \%)$ & $33(86.8 \%)$ & $52(51.5 \%)$ & 0.0002 \\
\hline \multicolumn{5}{|l|}{ Histology } \\
\hline Adenocarcinoma & $60(43.2 \%)$ & $21(55.3 \%)$ & $39(38.6 \%)$ & \\
\hline Squamous Cell Carcinoma & $35(25.2 \%)$ & $6(15.8 \%)$ & $29(28.7 \%)$ & \\
\hline Other NSCLC & $18(12.2 \%)$ & $3(7.9 \%)$ & $15(14.9 \%)$ & \\
\hline Clinical Diagnosis & $26(18.7 \%)$ & $8(21.1 \%)$ & $18(17.8 \%)$ & 0.29 \\
\hline \multicolumn{5}{|l|}{ Stage } \\
\hline IA & $120(86.3 \%)$ & $35(92.1 \%)$ & $85(84.2 \%)$ & \\
\hline IB/ IIA & $19(13.7 \%)$ & $3(7.9 \%)$ & $16(15.8 \%)$ & 0.28 \\
\hline \multicolumn{5}{|l|}{$\begin{array}{l}\text { Clinical T Stage (AJCC 7th } \\
\text { edition) }\end{array}$} \\
\hline $\mathrm{T} 1$ & $118(84.9 \%)$ & $34(84.4 \%)$ & $84(83.2 \%)$ & \\
\hline $\mathrm{T} 2$ & $21(15.1 \%)$ & $4(10.5 \%)$ & $17(16.8 \%)$ & 0.36 \\
\hline
\end{tabular}

${ }^{a} \mathrm{n}=138$ 
Table 2. Components of Modified Frailty Index

\begin{tabular}{|c|c|c|c|c|}
\hline & $\begin{array}{l}\text { All patients } \\
(\mathrm{n}=139)\end{array}$ & $\begin{array}{l}\text { Non-frail } \\
\text { patients (MFI } \\
<2 / 11 ; \mathrm{n}=38 \text { ) }\end{array}$ & $\begin{array}{c}\text { Frail } \\
\text { Patients } \\
(\mathrm{MFI} \geq 2 / 11 ; \\
\mathrm{n}=101)\end{array}$ & $\begin{array}{l}\mathrm{p} \text {-value } \\
\text { comparing } \\
\text { non-frail to } \\
\text { frail patients }\end{array}$ \\
\hline $\begin{array}{l}\text { Performance Status } \geq 2 \text { (partially or totally } \\
\text { dependent) }\end{array}$ & $52(37.4 \%)$ & $2(5.3 \%)$ & $50(49.5 \%)$ & $<0.0001$ \\
\hline $\begin{array}{l}\text { Impaired Sensorium (history of cognitive } \\
\text { impairment and delirium/clouding) }\end{array}$ & $5(3.6 \%)$ & $1(2.6 \%)$ & $4(4.0 \%)$ & 1.00 \\
\hline Diabetes Mellitus & $38(27.3 \%)$ & $1(2.6 \%)$ & $37(36.6 \%)$ & $<0.0001$ \\
\hline $\begin{array}{l}\text { Chronic or acute lung disease } \\
\text { (History of Chronic Obstructive Lung } \\
\text { Disease or Pneumonia } \leq 6 \text { months). }\end{array}$ & $67(48.2 \%)$ & $6(15.8 \%)$ & $61(60.4 \%)$ & $<0.0001$ \\
\hline Myocardial Infarction $\leq 6$ months & $5(3.6 \%)$ & $0(0.0 \%)$ & $5(5.0 \%)$ & 0.3227 \\
\hline $\begin{array}{l}\text { History of congestive heart failure } \leq 6 \\
\text { months }\end{array}$ & $1(0.7 \%)$ & $0(0.0 \%)$ & $1(1.0 \%)$ & 1.00 \\
\hline History of coronary or cardiac disease & $56(40.3 \%)$ & $2(5.3 \%)$ & $54(53.5 \%)$ & $<0.0001$ \\
\hline Hypertension on medications & $89(64.0 \%)$ & $13(34.2 \%)$ & $76(75.3 \%)$ & $<0.0001$ \\
\hline History of Transient Ischemic Attack & $17(12.2 \%)$ & $0(0.0 \%)$ & $17(16.8 \%)$ & 0.0036 \\
\hline $\begin{array}{l}\text { History of Cerebrovascular Accident/ Stroke } \\
\text { with neurologic deficit }\end{array}$ & $8(5.8 \%)$ & $1(2.6 \%)$ & $7(6.9 \%)$ & 0.4462 \\
\hline History of Peripheral Vascular Disease & $28(20.1 \%)$ & $1(2.6 \%)$ & $27(26.7 \%)$ & 0.0008 \\
\hline
\end{tabular}


Table 3. Death, Recurrence, and Toxicity by Frailty Status

\begin{tabular}{|c|c|c|c|c|}
\hline & $\begin{array}{l}\text { All patients } \\
\quad(n=139)\end{array}$ & $\begin{array}{l}\text { Non-frail } \\
\text { patients (mFI } \\
<2 ; \mathrm{n}=38)\end{array}$ & $\begin{array}{c}\text { Frail } \\
\text { Patients } \\
(\mathrm{mFI} \geq 2 ; \\
\mathrm{n}=101)\end{array}$ & $\mathrm{p}$-value \\
\hline \multicolumn{5}{|l|}{ Three-Year Survival Estimates } \\
\hline Overall Survival & $46.2 \%$ & $74.7 \%$ & $37.3 \%$ & 0.004 \\
\hline Cumulative incidence of lung cancer-specific death & $17.1 \%$ & $12.8 \%$ & $18.7 \%$ & 0.24 \\
\hline Cumulative incidence of non-cancer death & $36.7 \%$ & $12.5 \%$ & $44.1 \%$ & 0.02 \\
\hline \multicolumn{5}{|l|}{ Three-Year Recurrence-Free Rates } \\
\hline Primary Tumor & $90.6 \%$ & $100.0 \%$ & $86.8 \%$ & 0.05 \\
\hline Lobar & $84.9 \%$ & $100.0 \%$ & $79.0 \%$ & 0.01 \\
\hline Local/regional & $74.8 \%$ & $84.7 \%$ & $70.8 \%$ & 0.06 \\
\hline Distant Metastasis & $71.6 \%$ & $80.6 \%$ & $67.4 \%$ & 0.12 \\
\hline Recurrence-Free Survival at three years & $41.5 \%$ & $62.2 \%$ & $34.2 \%$ & 0.005 \\
\hline \multicolumn{5}{|l|}{ Toxicity } \\
\hline \multicolumn{5}{|l|}{ Highest Grade Esophagitis on CTCAE 4.0} \\
\hline Grade 1 & $1(0.7 \%)$ & $0(0.0 \%)$ & $1(1.0 \%)$ & \\
\hline Grade 2 & $1(0.7 \%)$ & $0(0.0 \%)$ & $1(1.0 \%)$ & \\
\hline Grade3 & $0(0.0 \%)$ & $0(0.0 \%)$ & $0(0.0 \%)$ & 1.00 \\
\hline \multicolumn{5}{|l|}{ Highest Grade Pneumonitis on CTCAE 4.0} \\
\hline Grade 1 & $5(3.6 \%)$ & $1(2.6 \%)$ & $4(4.0 \%)$ & \\
\hline Grade 2 & $3(2.2 \%)$ & $2(5.3 \%)$ & $1(1.0 \%)$ & \\
\hline Grade 3 & $1(0.7 \%)$ & $0(0.0 \%)$ & $1(1.0 \%)$ & 0.48 \\
\hline \multicolumn{5}{|l|}{ Highest Grade Chest Wall Pain on CTCAE 4.0 } \\
\hline Grade 1 & $6(4.3 \%)$ & $2(5.3 \%)$ & $4(4.0 \%)$ & \\
\hline Grade 2 & $3(2.2 \%)$ & $1(2.6 \%)$ & $2(2.0 \%)$ & \\
\hline Grade 3 & $1(0.7 \%)$ & $1(2.6 \%)$ & $0(0.0 \%)$ & 0.39 \\
\hline Rib Fracture & $4(2.9 \%)$ & $1(2.6 \%)$ & $3(3.0 \%)$ & 1.00 \\
\hline
\end{tabular}


Table 4: Univariate and Multivariate Cox Proportional Hazards Survival Analysis for patients with Stage I/II NSCLC treated with SBRT

\begin{tabular}{|c|c|c|c|c|}
\hline & \multicolumn{2}{|c|}{ Univariate Analysis $^{\mathrm{a}}$} & \multicolumn{2}{c|}{ Multivariate Analysis $^{\mathrm{p}}$} \\
\hline Variable & $\begin{array}{c}\text { Hazards Ratio } \\
(95 \% \mathrm{CI})\end{array}$ & $\mathrm{p}$-value & $\begin{array}{c}\text { Adjusted Hazards Ratio } \\
(95 \% \mathrm{CI})\end{array}$ & p-value \\
\hline Frail $(\mathrm{mFI} \geq 2 / 11)$ & $2.68(1.37-5.23)$ & 0.004 & $2.25(1.14-4.44)$ & 0.02 \\
\hline Age $>74$ & $1.04(0.65-1.64)$ & 0.88 & & 0.07 \\
\hline Female & $0.51(0.32-0.82)$ & 0.005 & $0.63(0.38-1.05)$ & 0.003 \\
\hline Pack-years of smoking & $1.01(1.01-1.02)$ & 0.0002 & $1.01(1.00-1.02)$ & \\
\hline BMI & $1.03(0.99-1.07)$ & 0.16 & & \\
\hline Previous Cancer Diagnosis & $0.75(0.48-1.19)$ & 0.23 & & \\
\hline Adenocarcinoma & $0.83(0.41-1.68)$ & 0.61 & & \\
\hline Squamous Cell Carcinoma & $1.47(0.71-3.04)$ & 0.30 & & \\
\hline Other NSCLC & $1.38(0.61-3.11)$ & 0.44 & & \\
\hline Clinical T Stage (T2 vs. T1) & $1.17(0.63-2.17)$ & 0.63 & & \\
\hline
\end{tabular}

${ }^{a}$ Univariate analysis represents a single variable Hazard Ratio analysis with Overall Survival (OS) as the outcome. 
Table 5: Secondary Analysis Showing Competing Risk for Non-Cancer Death with Lung Cancer as the Competing Event

\begin{tabular}{|c|c|c|}
\hline & \multicolumn{2}{|c|}{ Univariate Analysis $^{\mathrm{a}}$} \\
\hline Variable & $\begin{array}{c}\text { Hazards Ratio } \\
(95 \% \mathrm{CI})\end{array}$ & $\mathrm{p}$-value \\
\hline Frail (mFI $\geq 2 / 11)$ & $2.66(1.15-6.14)$ & 0.02 \\
\hline Age $>$ 74 (year) & $1.21(0.69-2.13)$ & 0.52 \\
\hline Female & $0.38(0.21-0.69)$ & 0.002 \\
\hline Pack-years of smoking & $1.01(0.998-1.02)$ & 0.12 \\
\hline BMI & $1.01(0.96-1.06)$ & 0.72 \\
\hline Previous Cancer Diagnosis & $0.86(0.49-1.52)$ & 0.61 \\
\hline Clinical Diagnosis (No & 1.00 & 0.98 \\
\hline Pathology) & $0.99(0.40-2.43)$ & 0.11 \\
Adenocarcinoma & $2.10(0.84-5.25)$ & 0.27 \\
\hline Squamous Cell Carcinoma & $1.76(0.65-4.80)$ & 0.88 \\
\hline Other NSCLC & & 0.97 \\
\hline Overall Stage (IB/IIA vs. IA) & $1.06(0.50-2.24)$ & $0.99(0.46-2.10)$ \\
\hline Clinical T Stage (T2 vs. T1) & & \\
\hline
\end{tabular}

${ }^{a}$ Univariate analysis represents a single variable Hazard Ratio analysis of Cumulative Incidence of noncancer death, with death from lung cancer as a competing risk. 